\title{
Intelligent Agents for Online Learning
}

\author{
Choonhapong Thaiupathump
}

Ph.D., Instructor, Computer Science Department

Faculty of Science, Chiang Mai University

Chiang Mai, THAILAND 50200

E-mail: cslchoth@science.cmu.ac.th

\section{John Bourne}

Ph.D., Professor of Electrical and Computer Engineering, Professor of Biomedical Engineering

Director, The ALN Center

Department of Electrical and Computer Engineering

Box 1570, Station B

Vanderbilt University

Nashville, TN. 37235

E-mail: John.Bourne@vanderbilt.edu

\section{J. Olin Campbell}

Ph.D., Associate Professor

Brigham Young University

E-mail: Olin_Campbell@byu.edu

The ALN Center

Vanderbilt University

Nashville, TN 37235

Telephone: 615 322-2118

Fax: 615 343-6449

\begin{abstract}
This research investigated the effects of applying intelligent agent techniques to an online learning environment. The knowbots (or Knowledge Robots) created for the research were intelligent software agents that automated the repetitive tasks of human facilitators in a series of online workshops. The study specifically captured experimental results of using knowbots in multiple sessions of an ALN (Asynchronous Learning Network) online workshop, Getting Started Creating Online Courses. The study used experimental groups and comparison groups to examine the association between the use of knowbots and workshop completion rates. Also examined were the effects of knowbots on other factors such as facilitation time and learner satisfaction. The findings indicated that the use of knowbots was positively associated with higher learner completion rates in the workshops. In addition, knowbots implemented a learning-support tool that reminded learners about deadlines. The support knowbots were found to be effective autonomous motivators. In sum, the results of this research suggest that the application of agent technology to online learning holds promise for improving completion rates, learner satisfaction, and motivation.
\end{abstract}

\section{KEYWORDS}

ALN, Intelligent agents, Online learning 


\section{INTRODUCTION}

Asynchronous Learning Networks (ALNs) appear to work best when there is a high level of online facilitation. Learners appreciate immediate feedback and the ability to get help rapidly. This finding has been shown in several ALN venues [1], [2]. The research reported in this paper describes a series of experiments designed to evaluate ways by which online courses (i.e., ALN courses) can be improved by the introduction of autonomous intelligent software agents. Intelligent Agents (IAs), termed "knowbots" can perform the duties of online facilitators for routine tasks. Checking computer code, responding to simple questions, reminding learners about the need to turn in assignments and potentially even grading essays [3] are among the types of things that intelligent agents can accomplish.

There are many challenges facing ALN. In distributed learning environments where there is the potential for losing the cohesiveness and spontaneity of the classroom experience, it is essential to understand how to improve the online learning experience so that it approaches and perhaps even exceeds more traditional instructional methods. The instant availability of a human tutor online would be ideal. However, providing this capability is no more realistic than continuously providing a human tutor for the traditional classroom-based learning experience. Cost and availability are limiting factors in supplying continuously attentive human tutors. Often students simply want questions answered and would be happy with any type of effective immediate feedback - human or machine. We think that feedback can be provided by intelligent agents in an on-demand format for certain types of information requirements. An augmented anytime capability is particularly important in learning environments in which online tutors may not be available for extended periods (e.g., due to differences in time zones or to late-night student study habits).

The research described in this paper was conducted to study the concept that autonomous intelligent agents can improve the learning effectiveness of ALN and improve learner satisfaction while simultaneously reducing cost. Our primary hypothesis was that introduction of IAs would increase the retention rate in an ALN workshop that we offer. The rationale for the choice of this outcome measure is that distributed learning courses often suffer from a large number of dropouts [4].

ALNs are networks of people who can learn anywhere and at anytime. The emphasis is on people learning with other people via the network. ALN has two components - the people-to-people component as facilitated with computer conferencing, and a self-study part [5]. The study of IAs bridges these components by providing help for the self-study part of ALN in a somewhat human way. A useful definition of an intelligent agent is given by Lieberman [6]:

An intelligent agent is any program that can be considered by the user to be acting as an assistant or helper, rather than as a tool in the manner of a conventional directmanipulation interface. An agent should as well display some, but perhaps not all, of the characteristics that are associated with human intelligence: learning, inference, adaptability, independence, creativity, etc.

Etzioni and Weld defined the term "software agent" as a computer program that behaves in a manner analogous to a human agent [7]. In essence, the term refers to software that supports a social interface metaphor -- a dialogue between a person and the agent. Various researchers proposed the following characteristics as desirable qualities of software agents [8]:

- Autonomy: An agent initiates and exercises control over its own actions in the following ways:

- Goal-oriented: accepts high-level requests indicating what a human wants and is responsible for deciding how and when to satisfy the requests. 
- Collaborative: does not blindly obey commands but can modify requests, ask clarification questions, or even refuse to satisfy certain requests.

- Flexible: actions are not scripted; the agent is able to dynamically choose which actions to invoke, and in what sequence, in response to the state of its external environment.

- Self-starting: unlike standard programs directly invoked by the user, an agent can sense changes in its environment and decide when to act.

- Temporal continuity: An agent is a continuously running process, not a one-shot computation that maps a single input to a single output and then terminates.

- Personality: An agent has a well-defined believable personality that facilitates interaction with human users.

- Communication ability: An agent can engage in complex communication with other agents, including people, to obtain information or enlist help to accomplish its goals.

- Adaptability: An agent automatically customizes itself to the preferences of its user on the basis of previous experience. It also automatically adapts to changes in its environment.

- Mobility: An agent can transport itself from one machine to another and across different system architectures and platforms.

Although no single agent has all these characteristics, several prototype agents embody a substantial fraction of them. There is little agreement about the relative importance of different properties, but most researchers agree that these are the characteristics that differentiate agents from single programs [7].

Selker provided another definition of Intelligent Agents that is close to use of the term in this paper [8]. He defined agents as computer programs that simulate a human relationship, by doing something that another person could otherwise do for you. For the purposes of ALN, our agent behaviors simulate what an expert workshop facilitator could do, including the following characteristics:

- Provide rapid, accurate and useful advice whenever needed

- Be activated on-demand or whenever need is observed by the agent

- Encourage learners to complete assignments, tasks or other learning requirements.

We use the term "knowbot" throughout this paper to define a program that uses intelligent agent techniques to provide assistance to workshop facilitators dealing with facilitation tasks as well as to workshop participants dealing with completing assignments.

The basic goal of our work is to investigate how we can improve the retention rate of students in ALN courses. The reason for choosing this goal is threefold: (1) our workshop uses assignments that require clear performance outcomes (mastery). Completion of the assignment demonstrates that the learner has developed the required knowledge and skills. Thus completion rate is a strong indicator of learning. (2) Retention rate in the workshop is an easily measurable and precise quantity and (3) retention rates in ALN courses are often not as good as rates in traditional courses. We chose to study the use of knowbots in an online workshop offered by the ALN Center at Vanderbilt University. The reasons for this choice were: (1) we had many learners who would agree to experimentation, (2) the workshop had no degree or credit associated with it and hence, the drop rate was much higher than in traditional courses in which credit is a motivator and (3) since we had built the workshop, it was feasible to integrate knowbot technology with the workshop. 


\section{METHOD}

This was an exploratory study to investigate whether the use of knowbots is related to learner completion rate in the workshop. At the outset we knew that completion rates in the first sessions offered were low, but we did not know whether use of knowbots would be associated with the higher completion rates - we only hypothesized that they would. We used an after-treatment with comparison group design to secure a preliminary look at the effectiveness of knowbots.

\section{A. Subjects}

The experimental population consisted of participants who took the ALN workshop Getting Started with Online Courses from May 1998 until January 1999. The ALN Center offers this eight-week online workshop about three times a year at Vanderbilt University. Over 1200 people have taken the course since 1997. We chose all participants from the May 1998 session of the workshop as the control group, which means that they completed the workshop without receiving help from knowbots. All participants from the September-1998 and January-1999 sessions of the workshop were selected as the treatment groups for the study. Although both September 1998 and January 1999 sessions were treatment groups, each session was observed separately since we suspected that completion rates might be affected by the knowbots growing more mature as we revised them. No changes in human facilitation methods were made between the two experimental groups.

Two hundred and twenty participants in May 1998 session of the workshop served as the control group. Ninety-eight participants in the September 1998 and 64 participants in the January 1999 sessions comprised the experimental groups.

Study participants from all three sessions of the ALN workshop came from the following areas: $42 \%$ education, $11 \%$ healthcare, $10 \%$ community colleges, and $7 \%$ training. The remaining $30 \%$ were in engineering, administration, art, government, or trade. While the study sample might not be considered a fair selection of treatment on the population, generalizability was not a primary goal at this research -- the major purpose of the study was to determine whether the use of knowbots affected retention in one program.

\section{B. The System Architecture}

Figure 1 presents the general architecture of the knowbot-based system. There are five basic components: the knowbots, the user/learner, the knowledge base, the repository of assignments and the interface with the facilitator. As shown, the knowbots sit between the instructor/facilitator and the learner, mediating the interaction. The internal architecture of the knowbots consists of user-interface agents, checker agents (autonomous agents that check submissions), e-mail agents and knowledge base modules:

- User-interface agents are graphical interface, web-based agents. A user commences interaction with knowbots through the use of these agents.

- The user-interface agents provide a user-friendly interface and act as a communication medium between the user and knowbots. Primarily, the functionality of the user-interface agents are to:

- Execute the checker agents by request

- Present information to the user

- Provide appropriate interfaces to execute actions such as requests for help

- Incorporate other relevant resources for the user

- Communicate with other agents (checker agent and e-mail agent) and with the knowledge base (e.g., track the interactions between users and system). 
- Email agents are responsible for generating, composing, organizing, and sending e-mails to both the facilitators and the participants. Examples of e-mails that are generated and sent to the participants are the assignment-status report, the assignment reminder and notification, and the message responding to a request for help. The e-mail agents compose the content of the e-mail by retrieving data from the knowledge base, associated with other relevant information, to assist the user in formulating queries.

- Checker agents are responsible for checking assignments for the participants. The agents can be invoked either by the scheduler or by the participant through the user-interface agents. The main functionality of the checker agents is to determine the completion status of the assignment based on the pre-defined knowledge of requirements for assignment completion. The checker agents record the results and access the knowledge base through the established Open Database Connectivity (ODBC) using the Cold Fusion Markup Language (CFML) [9]. Moreover, by checking each individual's assignment, the checker agent attempts to determine what particular knowledge each participant needs in order to complete the assignment. The agents provide extended knowledge based on the results of assignment checking and references (pointers) to the extended knowledge.

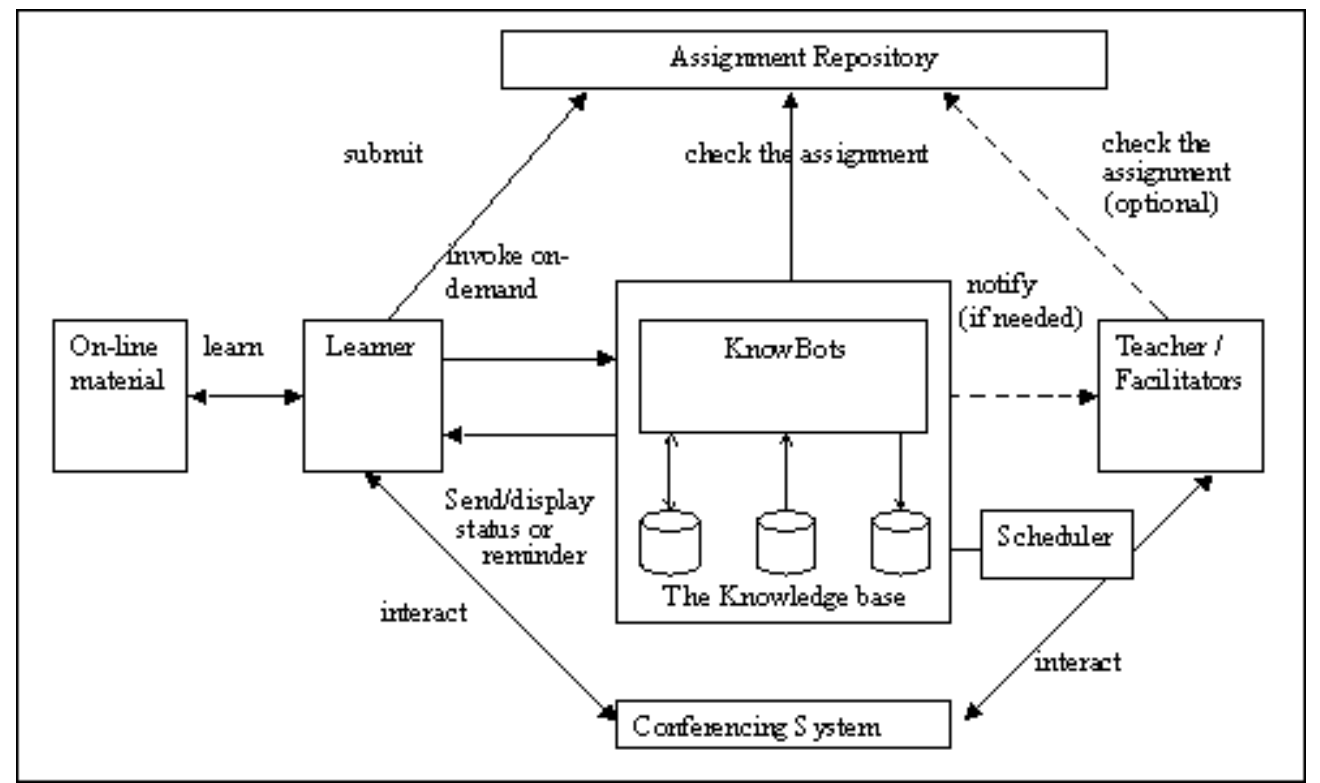

Arrows show one and two way interactions; dotted arrows designate optional paths.

Figure 1. General Architecture of the Knowbot System.

Table 1 displays a summary of the types of knowbots that were implemented: scheduled, on-demand and submission helper. Each scheduled knowbot sends a reminder and a report to each participant upon completion of a scheduled check. On-demand knowbots are invoked by the learner. These knowbots return results immediately to the requesting user. The submission helper knowbots are forms for submission of an assignment that assist the user in submitting the assignment. In addition, these knowbots notify the facilitator when the submission is made. Knowbots were tailor-made to support each different assignment. 


\begin{tabular}{|c|c|c|}
\hline $\begin{array}{l}\text { knowbot } \\
\text { name }\end{array}$ & $\begin{array}{l}\text { Scheduled (S)/ } \\
\text { On-demand } \\
\text { (OD) and } \\
\text { Submission } \\
\text { Helper } \\
\text { knowbots }\end{array}$ & Functionality/tasks \\
\hline $\begin{array}{l}\text { Posting } \\
\text { knowbot }\end{array}$ & $\mathrm{S}, \mathrm{OD}$ & $\begin{array}{l}\text { This knowbot looks for two types of messages posted in the } \\
\text { specified forum of the conferencing system by participants: one } \\
\text { is a self-introduction message, the other is a reply-to-another } \\
\text { message. The knowbot then sends a reminder and the results of } \\
\text { the scheduled check via e-mail to the participants. }\end{array}$ \\
\hline $\begin{array}{l}\text { Course } \\
\text { Review } \\
\text { knowbot }\end{array}$ & $\mathrm{S}, \mathrm{OD}$ & $\begin{array}{l}\text { The CR knowbot looks for at least } 3 \text { course-reviewed messages } \\
\text { posted in } 3 \text { different threads by the participants and sends a } \\
\text { reminder and the result of the checking by e-mail to the } \\
\text { participants. }\end{array}$ \\
\hline $\begin{array}{l}\text { Basic } \\
\text { HTML } \\
\text { knowbot }\end{array}$ & $\mathrm{S}, \mathrm{OD}$ & $\begin{array}{l}\text { The basic HTML knowbot checks the status of each } \\
\text { participant's personal homepage to determine if it contains the } \\
\text { required elements such as mail-to tag, bulleted list, etc. }\end{array}$ \\
\hline $\begin{array}{l}\text { HomePage } \\
\text { knowbot }\end{array}$ & $\mathrm{S}, \mathrm{OD}$ & $\begin{array}{l}\text { The homepage knowbot checks the status of course homepage } \\
\text { of the participants to determine if completion requirements are } \\
\text { met. }\end{array}$ \\
\hline $\begin{array}{l}\text { FrontPage } \\
\text { Features } \\
\text { knowbot }\end{array}$ & $\mathrm{S}, \mathrm{OD}$ & $\begin{array}{l}\text { The FP knowbot checks the participant's personal homepage for } \\
\text { advanced FrontPage features such as an image map or a } \\
\text { FrontPage theme. }\end{array}$ \\
\hline $\begin{array}{l}\text { Topic } \\
\text { knowbot }\end{array}$ & OD only & $\begin{array}{l}\text { This knowbot is invoked by the individual and determines if at } \\
\text { least one message has been posted into the specified forum in } \\
\text { the conferencing system about the required topic. The result is } \\
\text { displayed to the user. }\end{array}$ \\
\hline $\begin{array}{l}\text { Multimedia } \\
\text { knowbot }\end{array}$ & $\begin{array}{l}\text { Submission } \\
\text { Helper }\end{array}$ & $\begin{array}{l}\text { Each participant submits information via a knowbot. The } \\
\text { knowbot notifies the workshop facilitator about the submission, } \\
\text { provides a template for the facilitator to check the participant's } \\
\text { work, stores the results into the database and sends a } \\
\text { notification e-mail to report the result to the participant. }\end{array}$ \\
\hline $\begin{array}{l}\text { Discussion } \\
\text { Builder } \\
\text { knowbot }\end{array}$ & $\begin{array}{l}\text { Submission } \\
\text { Helper }\end{array}$ & Same functionality as Multimedia knowbot. \\
\hline
\end{tabular}

Table 1. Knowbot Functionality.

Figures 2, 3, and 4 capture screen shots that help illustrate how interaction with knowbots occurs. This learner interaction for one assignment helps illustrate how knowbots appear to the learner. Figure 2 shows how a URL can be submitted to a knowbot to be checked. 


\section{Submit the URLs - Microsoft Internet Explorer}

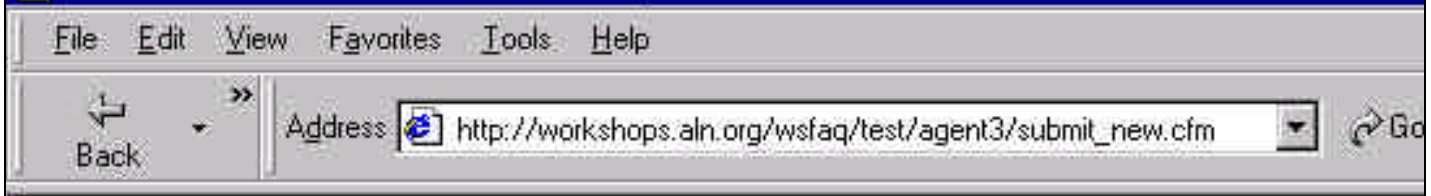

\section{Submit the URL of your homepage to the checker}

Enter the URL of your homepage:

http//wmw.aln.org/ws_choon/choon.htm

Enter email address:

choon@vusevanderbiltedu

Check Your Document

Check URL

\section{ClearForm}

Related links:-

- ALN WorkshopAssignment I-2

- ALN Workshop Conference

- Requirements for Certificate Completion

- Link to the FAQs

\section{Ahout this Checker:}

- Feedback and Comments

Figure 2. A Screen Shot of Knowbot Activation for Assignment \#I-2 in the ALN Workshop. 


\section{Assignment Checker}

In the Assignment \# I-2, your personal homepage should contain at least:

\begin{tabular}{|c|c|c|}
\hline HTML features & Status & Error details/Comments \\
\hline + 2 different headings & Complete & \\
\hline + 1 numbered list & Complete & \\
\hline + 1 bulleted list & Incomplete & Click here to see the detailed analysis. \\
\hline $\begin{array}{l}\text { + } 1 \text { hyperlink to another site or } \\
\text { page }\end{array}$ & Complete & \\
\hline $\begin{array}{l}\text { + } 1 \text { hyperlink to the workshop } \\
\text { homepage }\end{array}$ & Complete & \\
\hline + 1 mailto hyperlink (mailto:) & Complete & \\
\hline+1 horizontal line $<\mathrm{hr}>$ & Incomplete & Click here to see possible causes. \\
\hline + An image & Complete & \\
\hline
\end{tabular}

Note: Completion status for assignment is detemined based on the "Requirements for Certificate of Completion."

Click here or scroll down to see the datailed analysis.

\section{To update your status of this assignment in the checker database $=>$ click here.}

Use Back button of your browser to go back to the submission page or Back to the "Submit the URL of your homepage to the checker" form.

Did this checker help you to complete the assignment?
c Yes
$\mathrm{C}$ No
Didn't apply

Comments:

Figure 3. A Sample Screen Shot of Resulting Page (or Report)

From a Knowbot for Assignment \#I-2 in the ALN Workshop. 


\section{Detailed Analysis}

\section{Heading and Paragraph Tags Usage Summary}

- You have 1 complete Heading $1 \mathrm{Tag}(s)$ in your HTML code.

- You have 1 complete Heading2 Tag(s) in your HTML code.

- You do not have Heading 3 Tag in your HTML code.

- You do not have Heading4 Tag in your HTML code.

- You do not have Heading5 Tag in your HTML code.

- You do not have Heading6 Tag in your HTML code.

- You have 7 complete Paragraph Tag(s) in your HTML code.

\section{List and Formatting Tags Usage Summary}

- You have 1 complete Ordered (Numbered) List Tag(s) in your HTML code.

- You do not have Unordered (bulleted) List Tag in your HTML code.

- You do not have Definition List Tag in your HTML code.

- You do not have Bold text formatting Tag in your HTML code.

- You do not have Italic text formatting Tag in your HTML code.

\section{Hyperlink and Anchor Tags Usage Summary}

- You have 1 Mailto tags in your HTML code. martine.dawant@vanderbilt.edu.

- And found the following Hyperlink tags in your HTML code. Hyperlinks Status

http//www netlearning org/ws_betal/ $\mathrm{OK}$ http $/ /$ www netlearning org/ws_beta/page $2 . \mathrm{htm}$ $\mathrm{OK}$ $\mathrm{http} / / \mathrm{ww}$ wnetlearning org/ws_beta/myframe.htm $\mathrm{OK}$

Figure 4. A Sample Screen Shot of Detailed Analysis From a Knowbot for Assignment \#I-2 in the ALN Workshop. 


\section{Measurement Methods}

In this study, the workshop completion rate was used as a prime measure, a performance indicator, and a dependent variable of the study. Primarily, the completion of each assignment of the ALN workshop was criterion based. This means that the completion of each assignment was determined to be either pass or fail based on pre-specified criteria. The objective of the workshop was to teach faculty how to create online course materials. While we could not measure how many faculty actually created courses that were ultimately utilized for online education, the completion-rate measure served as an indicator of how much learning about the online courses creation process was secured via the workshop.

Other measurements of the study are:

- Number of times the participants used the knowbots system. These data were used to determine the association between the number of times the participants used the knowbots and the number of assignments completed by the participants.

- Number of messages posted in the conferencing system by the participants. It was assumed that the number of postings in the conferencing system by the participant could be related to the degree of participation of the participant. These data were used to determine whether the use of knowbots improves participation.

- Number of messages posted by workshop facilitators. It was also assumed that the number of postings in the conferencing system by the workshop facilitators could represent facilitation time. These data were used to determine whether the use of knowbots reduces the facilitation time.

These measures were used to examine how the use of knowbots affected completion rate, facilitation time, learner satisfaction, and motivation. Messages related purely to course logistics were removed from the message count.

Data to be analyzed for the study were obtained mostly from the databases maintained by the knowbots system. In addition, a set of survey questionnaires was sent to all participants to obtain additional data. Participant response rates of the survey were 43\% from the May 1998 session, and 50\% from the September 1998 and January 1999 sessions.

\section{Analysis Methods}

The knowbots study primarily tested the hypothesis that an intelligent agent improves learner retention rate. A method was devised to compare the performance of participants between two versions of the ALN workshop: One version of the workshop received help from the knowbots and the other did not. The t-test analysis was performed to examine whether there is a statistical difference between the average number of assignments completed by the participants from both groups. Correlational analysis was used to examine the association between the number of times the knowbots were used and the number of assignments completed by the participants of each group.

A comprehensive analysis of the survey results led to a better understanding of the effects of knowbots on completion and on other factors, such as motivation, confidence, learning behavior, and user satisfaction. Ratings were given on 1-to-5 Likert-type response scale where 1="very low, very poor, or not at all" and $5=$ "very high or excellent."

\section{RESULTS}

The percentage of assignment completions and workshop completions of the May 1998 session (before using the knowbots system) is presented in Figure 2 below. Figure 3 shows the percentage of workshop and assignment completions of the September 1998 and January 1999 sessions (after introducing 
knowbots). Figures 2 and 3 clearly show that the two sessions in which participants received help from knowbots (September 1998 and January 1999 sessions) had higher completion rates than the May 1998 session, when no help was provided by knowbots.

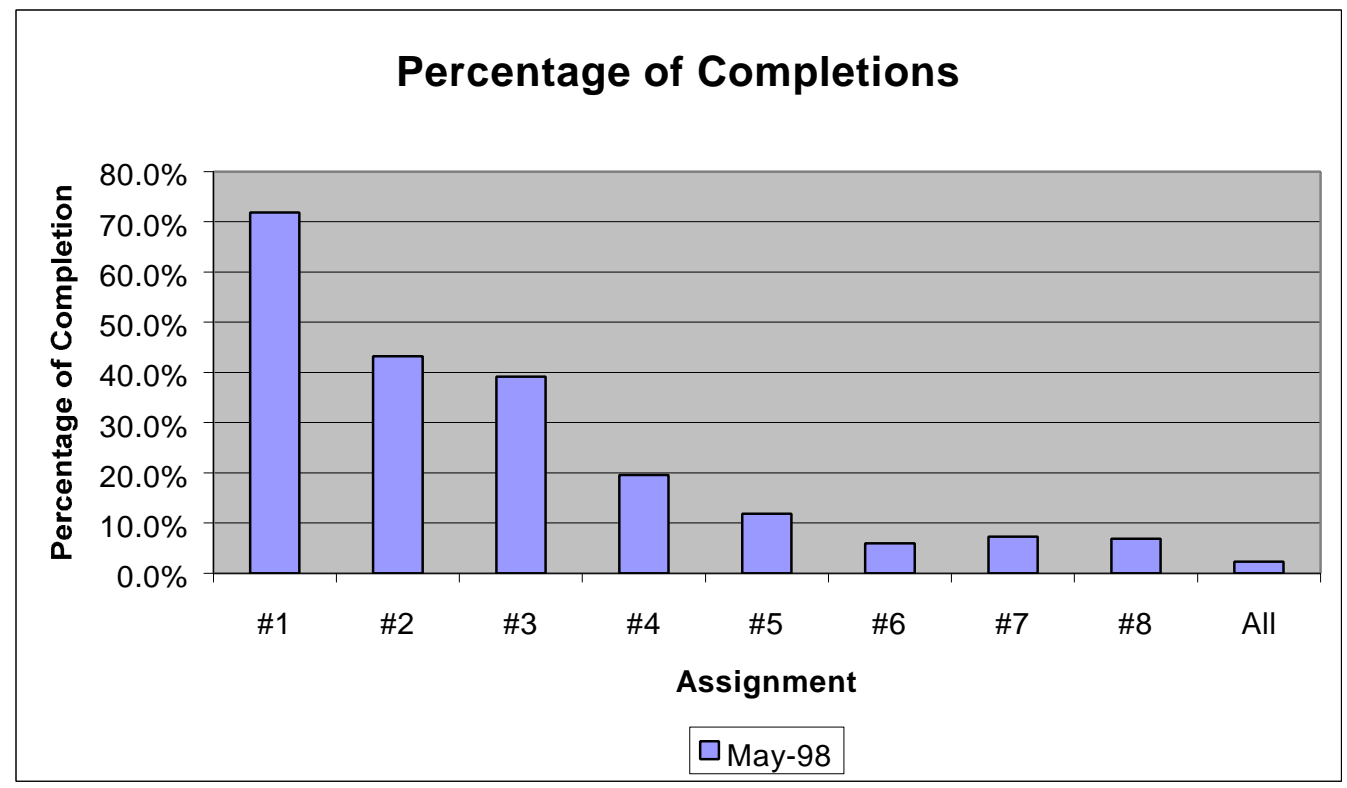

Figure 5. Percentage of Workshop Completion Before Introducing Knowbots.

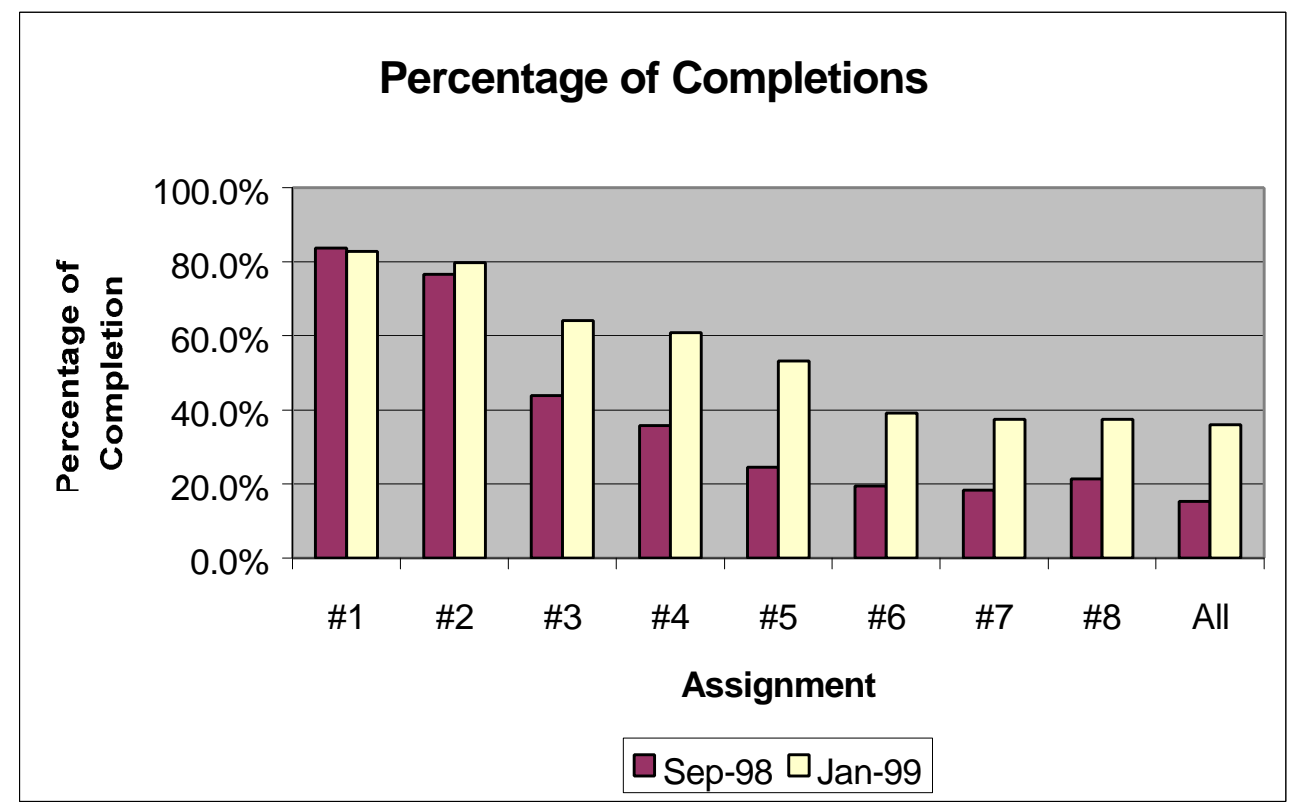

Figure 6. Percentage of Workshop Completions After Introduction of Knowbots.

There was no evidence found to indicate that there were population differences among the experimental groups. The constituency of the groups varied among different disciplines (e.g., nursing, engineering), but no group dominated any session. As an indicator of differences among the groups after introduction of knowbots, t-test analyses were employed. These tests would indicate if there were a significant difference between the average number of assignment completions of the May 1998 session and the 
average number of assignment completions of the September 1998 session, and between those of the May 1998 session and the January 1999 session.

Results from t-test analyses are presented in Figures 7 and 8.

\section{Two Sample t-Test and Confidence Interval}

Two sample t-tests for Number of Assignments Completed in September 1998 session vs. Number df Assignments Completed in May 1998 session

\section{Number of Assignments}

Completed by Participants N Mean StDev SE Mean

$\begin{array}{lllll}\text { September } 1998 \text { session } & 98 & 3.08 & 2.61 & 0.25\end{array}$

$\begin{array}{llll}\text { May } 1998 \text { session } \quad 220 & 2.14 & 2.22 & 0.15\end{array}$

95\% Confidence Interval for $\mu_{\text {September } 1998}-\mu_{\text {May 1998 }}(0.36,1.52)$

t-test of $\mu_{\text {September } 1998}=\mu_{\text {May 1998: }} \mathrm{t}=3.20, \mathrm{p}=0.0016, \mathrm{DF}=180$

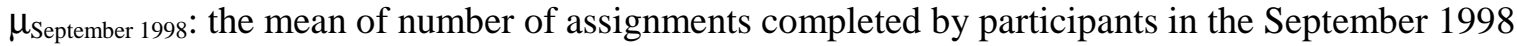

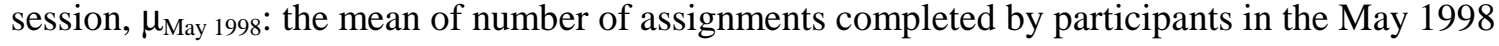
session

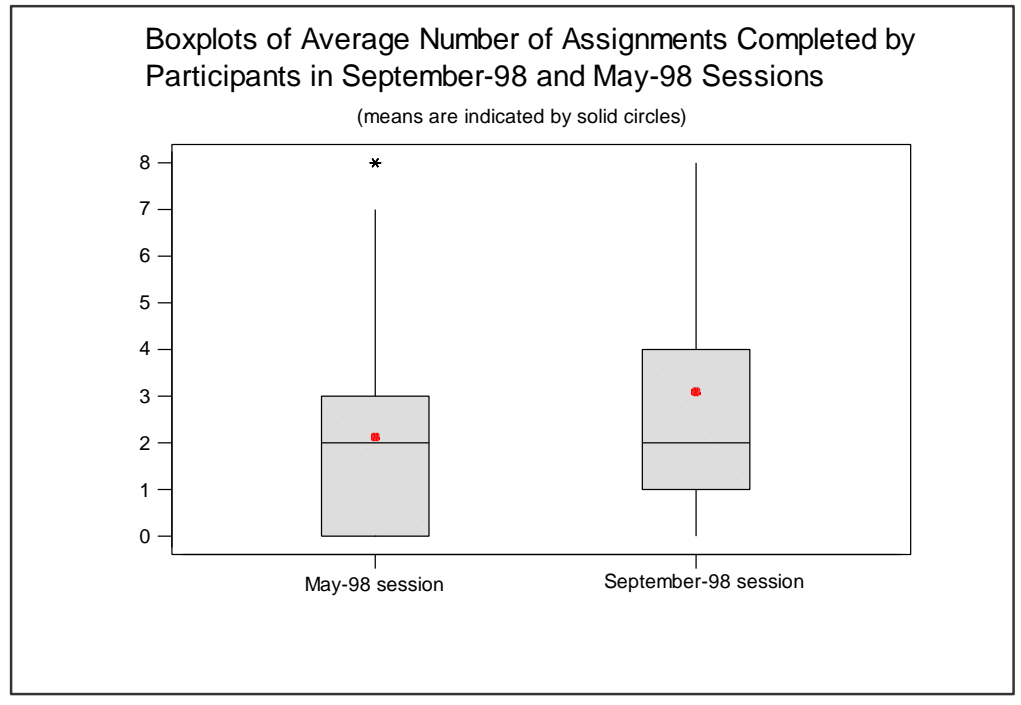

Figure 7. T-Test Analysis Between Number Of Assignments Completed By Participants From the May 1998 Session and the September 1998 Session. 


\section{Two Sample t-Test and Confidence Intervals}

Two sample t-test for Number of Assignments Completed in January 1999 session vs. Number of Assignments Completed in May 1998 session

\section{Number of Assignments}

Completed by Participants

January 1999 session

May 1998 session

$\begin{array}{rlll}\mathbf{N} & \text { Mean } & \text { StDev } & \text { SE MeanS } \\ 64 & 4.58 & 3.04 & 0.38 \\ 220 & 2.14 & 2.22 & 0.15\end{array}$

95\% Confidence Interval for $\mu_{\text {January 1999 }}=\mu_{\text {May 1998: }}(1.62,3.25)$

t-test of $\mu_{\text {January } 1999}=\mu_{\text {May 1998: }}: t=5.96, p=0.0000, D F=83$

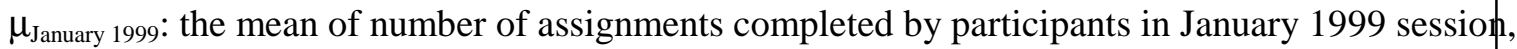

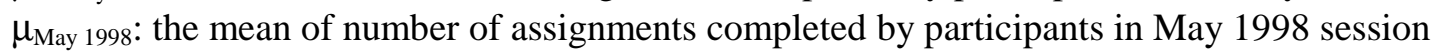

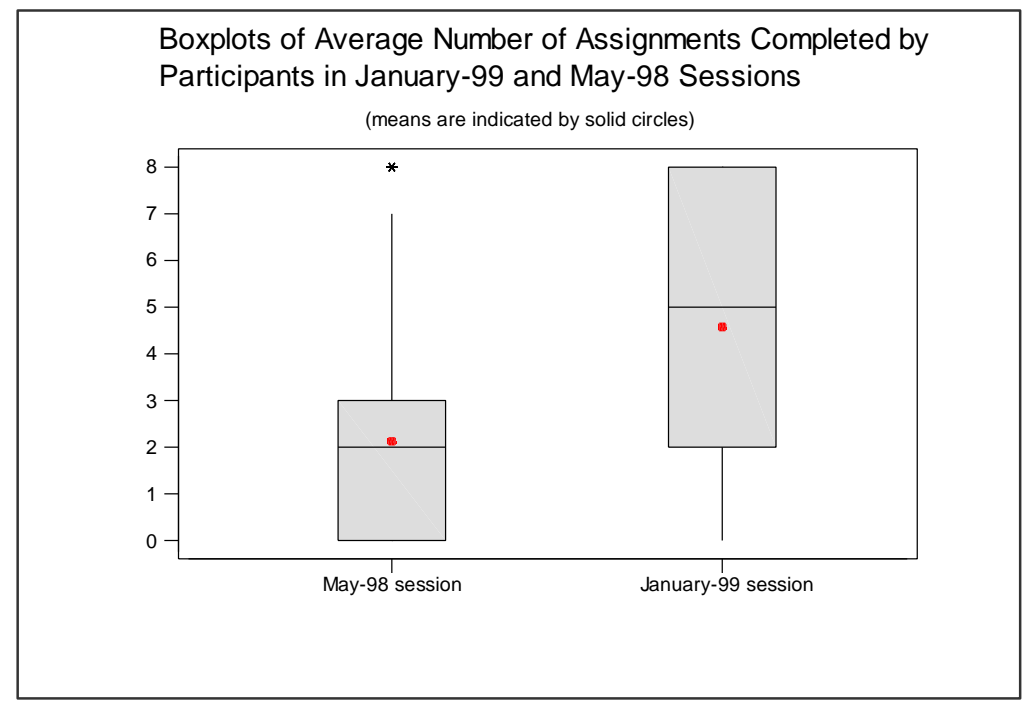

Figure 8. T-Test Analysis Between Number Of Assignments Completed By Participants From May 1998 Session and January 1999 Session.

The boxplots indicate that the participants from the September 1998 and the January 1999 session completed more assignments than the participants from the May 1998 session. The line drawn across each boxplot indicates the median, or middle, of the data. The bottom edge and top edge of the box mark the first $\left(25^{\text {th }}\right.$ percentile $)$ and third $\left(75^{\text {th }}\right.$ percentile $)$ quartiles, respectively.

The obtained t-values from both t-tests were greater than the critical value of the pre-specified level of significance $(\alpha=.05)$. They were also significant at $\alpha=.01$. Hence, it can be concluded that there is a significant difference in the number of assignment completions between the groups that received help from knowbots (September 1998 and January 1999 sessions) and the group that did not receive help from knowbots (May 1998 session). 
A correlation analysis was conducted comparing the number of times learners used the knowbots and the number of assignments completed by the participants from the September 1998 and January 1999 sessions. The results are presented in Table 2.

\begin{tabular}{|l|c|c|}
\hline & Sept 1998 session & Jan 1999 session \\
\hline Correlation value, $r$ & 0.734 & 0.655 \\
& $0.625 \leq \rho \leq 0.891$ & $0.484 \leq \rho \leq 0.777$ \\
\hline Decision (correlation level) & Moderate positive & Moderate positive \\
\hline
\end{tabular}

Table 2. Correlation Analysis Between Number of Times Using the Knowbots and Number of Assignments Completed By The Participant.

The computed correlation values from both sessions were greater than the pre-specified critical value (.05) and also greater than the .01 level. The data from the correlation analysis suggest that there was a moderate positive correlation between the number of times participants used the knowbots and the number of assignments completed by the participants in the session that had help from knowbots.

In addition to investigating the effects of the use of knowbots on the learner retention rate, we also investigated other possible effects of using knowbots in the workshop. The following two additional hypotheses were proposed:

- The use of knowbots is associated with greater participation of workshop participants.

- The use of knowbots in the ALN workshop is associated with reduced facilitation time.

To measure the degree of participation of workshop participants, it was assumed that the number of messages posted by the participants in the conferencing system was related to the degree of participation in the workshop. The number of postings in the conferencing system by the participants from each session is shown in Table 3.

\begin{tabular}{|l|c|c|c|}
\hline & $\begin{array}{c}\text { May } \\
\mathbf{1 9 9 8}\end{array}$ & $\begin{array}{c}\text { Sept } \\
\mathbf{1 9 9 8}\end{array}$ & $\begin{array}{c}\text { Jan } \\
\mathbf{1 9 9 9}\end{array}$ \\
\hline Number of participants & 220 & 98 & 64 \\
\hline Total number of postings by participants & 2300 & 1639 & 1160 \\
\hline Average number of postings per participant & 10.45 & 16.72 & 18.13 \\
\hline Standard deviation & 11.7 & 17.0 & 14.6 \\
\hline
\end{tabular}

Table 3. Number of Postings by Participants in the Conferencing System.

The average number of messages posted by the participants from each session of the workshop is shown in Figure 9. 


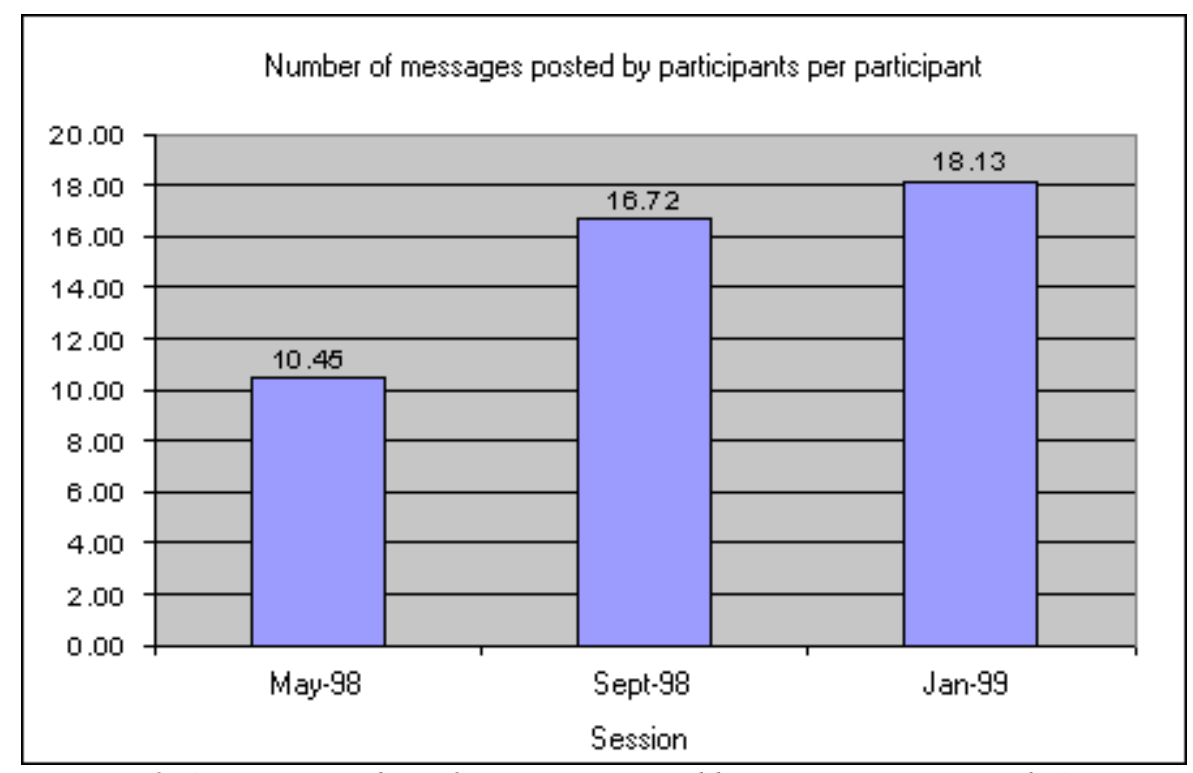

Figure 9. Average Number of Messages Posted by Participants in Each Session.

Figure 9 indicates that the average number of messages posted by the participants in the September 1998 and January 1999 sessions increased compared to the average number of messages posted by participants in the May 1998 session. Thus, there is support for the theory that the use of knowbots is associated with greater participation.

To measure the facilitation time, it was assumed that the total number of messages posted by facilitators in the conferencing system is likely to be directly related to the total estimated time of workshop facilitation.

Table 4 presents data obtained from the conferencing system's database of each workshop session. The total facilitation time on item \#4 (total number of minutes of facilitation time) was determined from the amount of time estimated that the facilitator spent responding to questions (or request-for-help messages) posted in the conferencing system. First, the total number of messages posted in the conferencing system was gathered, accompanied by the question or message that each message responded to. Then, the time spent was rated according to the complexity of the messages. It was assumed that the more complex the message or question, the more time the facilitator spent answering the questions. 


\begin{tabular}{|c|l|c|c|c|}
\hline & \multicolumn{1}{|c|}{ Description } & $\begin{array}{c}\text { May } \\
\mathbf{1 9 9 8}\end{array}$ & $\begin{array}{c}\text { Sept } \\
\mathbf{1 9 9 8}\end{array}$ & Jan 1999 \\
\hline 1 & Number of participants & 220 & 98 & 64 \\
\hline 2 & $\begin{array}{l}\text { Total number of messages posted in the } \\
\text { conferencing system }\end{array}$ & 2832 & 2240 & 1419 \\
\hline 3 & Total number of facilitation messages & 349 & 329 & 158 \\
\hline 4 & Total facilitation time (minutes) & 3019 & 2015 & 994 \\
\hline 5 & $\begin{array}{l}\text { Average facilitation time spent per } \\
\text { participant (minute) }\end{array}$ & 13.7 & 20.6 & 15.5 \\
\hline
\end{tabular}

*Total time spent was determined from the total amount of time facilitators spent on each facilitation message. Time spent on each message was estimated based on the complexity of each message, assuming that the more complex messages take more time for the facilitator to answer.

Table 4. Data on Estimated Facilitation Time.

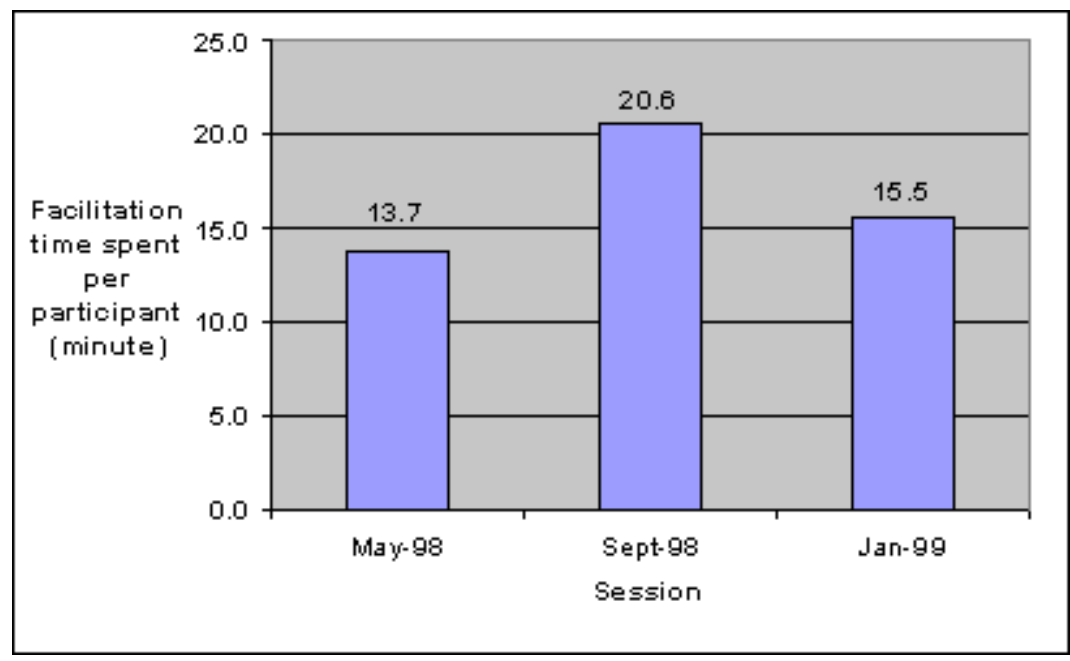

Figure 10. Estimated Average Facilitation Time of Each Workshop Session.

Figure 10 shows that the result of this analysis is clearly contrary to the initial expectation that the use of knowbots would reduce facilitation time. We conducted a detailed analysis of the facilitator/learner interactions, expecting that the effort of facilitators would be reduced. Instead, we found more detailed responses by facilitators and more questions from the learners in the workshop. While a surprise, a possible conclusion is that knowbots introduced the useful and unexpected addition of enhanced humanto-human communication to the two knowbot-enabled workshops that was not present in the control workshop. 
Table 5 summarizes the results as related to our initial hypothesis.

\begin{tabular}{|l|l|}
\hline \multicolumn{1}{|c|}{ Hypothesis } & \multicolumn{1}{|c|}{$\begin{array}{c}\text { Result from } \\
\text { Experiments }\end{array}$} \\
\hline $\begin{array}{l}\text { Adopting intelligent agent techniques in the ALN workshop } \\
\text { improves completion rates }\end{array}$ & Positively associated \\
\hline $\begin{array}{l}\text { More frequent use of knowbots is associated with a higher } \\
\text { number of assignment completions }\end{array}$ & $\begin{array}{l}\text { Moderately positively } \\
\text { associated }\end{array}$ \\
\hline $\begin{array}{l}\text { The use of knowbots is associated with increases in the } \\
\text { participation of workshop participants }\end{array}$ & Positively associated \\
\hline $\begin{array}{l}\text { The use of knowbots to the ALN workshop is associated } \\
\text { with reduced facilitation time }\end{array}$ & $\begin{array}{l}\text { Contradicts; but } \\
\text { introduces new findings } \\
\text { (see text) }\end{array}$ \\
\hline
\end{tabular}

Table 5. Summary of Hypothesis Testing.

\section{DISCUSSION}

We found that using intelligent agents in our online workshops showed a very positive association with a higher completion rate of the workshops. However, due to the fact that the research is correlational in nature, we cannot assert that the use of knowbots had a direct effect on the completion rate. Nevertheless, we can say (1) that there was a dramatic increase in completion rate in the treatment that employed knowbots, and (2) the majority of the learners expressed positive attitudes toward using the knowbots, specifically as a tool that helped motivate them to complete the workshop.

\section{A. Knowbots and Facilitation Time}

Results from the study indicate that the use of knowbots did not help reduce workshop facilitation time when they were used for the first time in the September 1998 session. There are two possible explanations for this outcome. First, knowbots for the September 1998 session were created concurrently with the workshop offering. The evidence from the study indicated that knowbots might not have been mature enough at that time. Second, there were no explicit directions or instructions provided to the participants about how to use the knowbots in the September 1998 session until after the workshop had begun. Some participants of that particular session did not understand that they had to use the knowbots in order to verify the completion status of their assignments. Hence, the lack of pre-workshop information may have resulted in causing the participants some degree of confusion and frustration in completing the workshop. The results from the survey questionnaire also support this observation. These problems with initial startup may well have caused the increase in facilitator time spent clarifying how to use the knowbots.

Many important questions remain unanswered. The knowbots system is designed to automate the facilitator's assignment-checking tasks and thus, reduce the cost of facilitation of online courses. Ultimately learning time may be reduced by providing more rapid responses than can be provided by human facilitation. It is important to examine in more detail the time the facilitators spend on various tasks. In our current study, we were unable to precisely measure the time facilitators spent on various specific tasks, such as the assignment-checking tasks before and after using the knowbots. In subsequent studies, it would be important to evaluate changes in facilitation time due only to the activities that the 
knowbots performed on a human facilitator's behalf. This information would assist in understanding if knowbots can ultimately reduce facilitation cost.

\section{B. Knowbots as a Motivational Tool}

The results from this study supported the notion that intelligent agents in the form of knowbots can be used as a motivational tool. The results from the correlation analysis indicated a positive correlation between the number of times the participants used the knowbots and the number of assignments completed by the participants (Table 4). Results from the survey analysis on Motivation indicated that features of knowbots such as encouraging e-mail, immediate feedback, and reminders helped motivate the participants to complete the assignments and the workshop. These features are of positive benefit to the workshop when knowbots are present in the learning environment. Specifically, the immediate feedback that the on-demand knowbots provided after checking the participant's assignment helped motivate the learners to stay focused on completing the assignments. Explicit directions on how to fix problems in an assignment were found by learners to be useful feature. Providing explicit help to learners improved the completion rate of the subsequent session. Our conclusion is that knowbots can be a strong motivational tool.

\section{Knowbots as a Tutor}

From qualitative analysis of data obtained through the survey of participants, a very high number of learners in the knowbot cohort had positive attitudes toward the use of knowbots as a learning tutor. A likely reason is that knowbots provided immediate feedback to them when they needed it. Immediate feedback, including presenting learners with possible solutions, helped the learners to quickly solve their problems. Other than reporting the assignment checking status, immediate feedback also provided other assistance about where to find information in the learning materials and where to seek further help. In these cases, knowbots helped learners reduce the time required to find answers to their problems. Anytime feedback also facilitated self-paced learning. Some students prefer to move at their own rate; it is indeed possible that the knowbot system supported such students better than group-oriented exercises.

\section{Knowbots as a Human-to-Human Interaction Facilitator}

Although we initially hypothesized that knowbots would reduce the need for facilitator communication with learners, instead, we found increased interaction. This finding suggests that our knowbots provided another mechanism for stimulating discussions and people-to-people interactions, not the converse. While we must reject our initial hypothesis, the results are still encouraging since improving human-tohuman interaction remains a central part of ALN. Nevertheless, this finding may flag a potential problem in attempting to reduce cost through automation - that is, automation of this type may serve to improve human-to-human communication since facilitator time appears to expand to fill the time saved by the knowbot agents.

Finally, interaction with a human facilitator should remain an option for learners to request further help when needed, even after adopting intelligent agents into the learning environment. Human interaction is important for an educational environment. We suspect that learners may prefer a human facilitator if the feedback is rapid enough. When human facilitation is not available due either to cost or time constraints, the intelligent agent approach appears to offer an interesting alternative.

Knowbots are an example of using intelligent agent techniques to automate the assignment checking tasks for a human facilitator. Our experiments demonstrate that adopting an intelligent agent to online learning is indeed feasible. More experiments will likely reveal new paradigms for the use of knowbots in ALNs. 
Intelligent agents can be employed to shift online learning paradigms away from a traditional learning environment to concentrate instead on a user's individual needs. An online learning environment with intelligent agents can help move students toward an apprenticeship, or learn-while-doing, approach. The knowbots system demonstrates that agent technology can successfully work in place of a human facilitator to give immediate responses in an on-demand learning environment.

In conclusion, the results from the study indicated that use of intelligent agents is significantly associated with learner progress. The knowbot system demonstrated that agent technology can supplement a human tutor to give personalized instruction and support human-to-human interactions.

\section{ACKNOWLEDGEMENT}

This paper is based on a Ph.D. dissertation by Choonhapong Thaiupathump, completed in July 1999 at Vanderbilt University. The dissertation may be found online in the Vanderbilt University library collection of dissertations. The authors acknowledge the support of the Alfred P. Sloan Foundation, the School of Engineering at Vanderbilt, and the Government of Thailand. The help of Art Brodersen, Martine Dawant, Jason Mann, Eric McMaster, John Crocetti, Joy Holly, Richard Shiavi and Gautam Biswas is gratefully acknowledged. Reviews from several members of the ALN community are also acknowledged.

\section{REFERENCES}

1. Kashy. E., Morrissey, D.J., Tsai, Y., and Wolfe, S.J., An Introduction to CAPA: A Versatile Tool for Science Education, MSUCL-971, September 1995.

2. Sapir, M., The WebTester and the Linear Algebra WebNotes, The ALN Magazine, Vol.3, Issue 1, July 1999. www.aln.org.

3. McCollum, K., How a Computer Program Learns to Grade Essays, The Chronicle of Higher Education, September 4, 1998.

4. Oakley, B., A Virtual Classroom Approach to Learning Circuit Analysis, IEEE Trans. on Education, 39, , pp. 287-296, 1996.

5. Bourne, J. R., Net-Learning: Strategies for On-Campus and Off-Campus Network-enabled Learning, Journal of Asynchronous Learning Networks, Vol .2, No. 2, pp. 70-88, Sept., 1998.

6. Lieberman, H., Autonomous Interface Agents, CHI 97 Papers, pp. 22-27, March 1997.

7. Etzioni, O., and Weld D. S., Intelligent Agents on the Internet: Fact, Fiction, and Forecast, IEEE Expert, pp. 44-49, August 1995.

8. Selker, T., Coach: A Teaching Agent that Learns, Communications of ACM, Vol. 37. No. 7.

9. Cold Fusion Markup Language, Allaire Corporate, Boston, MA, 1999. www.allaire.com 